\title{
Motivação no trabalho: Uma Avaliação do nível de Satisfação de Policiais Militares
}

\author{
Marcos Eduardo de Françal ${ }^{1}$; Hesler Piedade Caffé Filho ${ }^{2}$
}

\begin{abstract}
Resumo: O presente artigo teve como objetivo avaliar se é possível provocar a motivação dos policiais militares do Estado da Bahia, especialmente os que servem na Companhia Independente de Policiamento Tático na cidade de Juazeiro, através da implementação de eventos motivacionais, tais como palestras, seminários, oficinas, show, entre outros artifícios capazes de melhorar o ânimo dos servidores. Para constatar que é possível melhorar o nível de satisfação do servidor militar estadual da Bahia, foram aplicados questionários objetivos com o público alvo da pesquisa. O objetivo geral da pesquisa foi avaliar o nível motivacional dos servidores, antes e após participarem de palestra motivacional. A pesquisa revelou um alto nível de insatisfação dos colaboradores no tocante quanto à instituição e à falta de reconhecimento do seu trabalho. Mostrou também que, apesar dos gestores entenderem a importância e necessidade, a instituição não possui uma política de investigação de níveis motivacionais da tropa o que ocasiona uma perda de produtividade no resguardo da segurança pública. Por outro lado, foi possível perceber que os entrevistados têm plena consciência da importância do seu trabalho para com a instituição e a sociedade, mantêm um bom relacionamento com seus colegas de trabalho e acreditam que é possível melhorar com a adoção de uma política voltada para a satisfação do público interno. Assim, esta pesquisa pode subsidiar os gestores públicos na tomada de decisão quanto ao estudo e aplicação dessas políticas.
\end{abstract}

Palavras-Chave: Motivação, Reconhecimento, Qualidade de vida.

\section{Motivation at Work: An Evaluation of the level of Satisfaction in Military Police}

\begin{abstract}
This study aimed to assess whether it is possible to cause the motivation of the military police of the state of Bahia, especially those serving in the Company Independent Policing Tactical in the city of Juazeiro, through the implementation of motivational events, such as lectures, seminars, workshops, show, among other devices that improve the mood of the servers. To see that it is possible to improve the level of satisfaction of the state military server of Bahia, they were applied questionnaires goals with the target audience of the research. The overall objective of the research was to evaluate the motivational level of servers before and after participating in motivational speech. The survey revealed a high level of dissatisfaction of employees with respect as the institution and the lack of recognition of their work. It also showed that despite the managers understand the importance and necessity, the institution does not have a motivational levels of research policy troop which causes a loss of productivity in the public security guard. On the other hand, it was revealed that the respondents are aware of the importance of their work to the institution and society, maintain a good relationship with your colleagues and believe that it is possible to improve with the adoption of a policy for satisfaction of the workforce. Thus, this research can inform public managers in decision making about the study and application of these policies.
\end{abstract}

Keywords : Motivation, Recognition, Quality of life .

\footnotetext{
${ }^{1}$ Marcos Eduardo de França, Bacharel em Administração pela Universidade Norte do Paraná - UNOPAR, Brasil (2014) e Pós graduando em Gestão Pública pela Universidade Federal do Vale do São Francisco, Brasil (2016). E-mail: mfranca.tst@ hotmail.com;

${ }^{2}$ Hesler Piedade Caffé Filho, Especialização em Marketing Institucional pela Faculdade São Francisco de Juazeiro, Brasil (2009), Professor de Pós Graduação da Universidade Federal do Vale do São Francisco, Brasil.
} 
Id on Line Revista Multidisciplinar e de Psicoloqia

Id on Line Revista Multidisciplinar e de Psicologia

\section{Introdução}

A violência é um dos principais problemas sociais da atualidade brasileira. $\mathrm{O}$ povo clama por mais segurança, por melhores condições de poder resguardar a vida e o patrimônio. É sabido que a criminalidade sempre esteve presente no meio da sociedade e seu enfrentamento exige conhecimento técnico sobre os diversos fatores que influenciam para sua evolução, como também sugere que seja implementada uma capacitação continuada com objetivo de instruir e motivar os atores envolvidos diretamente com a causa de redução da violência.

O estudo, implementação e avaliação de políticas públicas para a segurança pública são temas altamente discutidos na esfera governamental e social. Apresenta-se desta forma, um desafio ao Estado, com a colaboração da sociedade, para que estas políticas sejam colocadas em prática e que surtam os efeitos esperados e assim a população brasileira possa gozar de um verdadeiro estado de segurança.

Visualizar e conviver com a violência e suas consequências na sociedade é angustiante, Giddens (1966). E em meio a este cenário caótico a Polícia Militar surge como a principal resposta às necessidades da população e neste momento não é possível visualizar uma categoria de profissionais mais afetada do que o policial militar. Dessa forma entende-se que este profissional merece uma atenção especial.

Ao analisar os aspectos da violência no Brasil, é possível observar que além de todas as discussões sobre a questão macro da segurança pública é necessário também dar atenção a estes profissionais que lidam diretamente no combate ao crime. Como eles enxergam a questão? O quanto estão preparados para este árduo trabalho? Qual o nível de empolgação ou motivação para o trabalho? E qual o grau de envolvimento neste gigantesco projeto de enfrentamento à criminalidade? Esses são alguns questionamentos que devem ser observados quando se tratar de segurança pública, visto que sem os profissionais de área nenhum projeto pode subsistir, mesmo com todo o esforço do Estado e apoio popular. Se estes profissionais não forem adequadamente tratados é inútil qualquer trabalho no sentido de reduzir os índices de criminalidade e garantir a paz social.

A atuação policial por si só não é suficiente para estabelecer o total controle da criminalidade, visto que este resultado extrapola os limites de atuação policial, sendo necessário a intervenção de vários outros atores nesse cenário de complexa compreensão. Mas os anseios da sociedade, na vulnerabilidade que se tem diariamente frente às situações de risco, no momento de medo que a sufoca, cobra da polícia mais do que ela pode atender e essa carga de cobrança deixa os profissionais de polícia sobrecarregados e com isso é desencadeada uma série de problemas que podem afetar a saúde e o nível de produtividade e efetividade da atividade policial e assim mina-se também a qualidade de vida dos profissionais que atuam na linha de frente da batalha contra a violência. 
Id on Line Revista Multidisciplinar e de Psicologia

Id on Line Revista Multidisciplinar e de Psicologia

Nesse contexto, surge então a figura do gestor público, com o desafio de visualizar o cenário interno da situação dos profissionais que fazem a segurança pública na linha de frente dessa batalha contra o crime, mais precisamente dos policiais militares que estão expostos ao risco diário do trabalho policial, vivenciado constantemente um clima de medo e estresse. Além de tomar ciência da situação o gestor público tem o papel fundamental de dar diligência à aplicação de políticas que venham garantir a integridade física, psicológica, emocional e social dos policiais sob sua gerência.

Partindo do pressuposto de que é impossível garantir a segurança das pessoas quando o principal ator da segurança pública não se sente seguro, nem tampouco percebe o reconhecimento devido e menos ainda se sente motivado para o trabalho, é que a aplicação de políticas desta natureza deve ser estudada e aprimorada até que se alcance um nível de profunda institucionalização para se tornar em cultural organizacional, fundamental a qualquer órgão que prese pela vida e satisfação do seu público interno.

Assim, este trabalho pretende proporcionar conhecimento sobre a aplicação de eventos motivacionais no interior das unidades policiais estudadas com o objetivo de analisar quais as questões envolvidas na motivação ou desmotivação na realização de suas tarefas profissionais cotidianas e, tentar mostrar se é possível provocar a motivação dos colaboradores pesquisados através de eventos apropriados. Dessa forma, serão explicitados exemplos de boas práticas para a gestão de pessoas e mecanismos que podem proporcionar melhor qualidade de vida aos servidores da segurança pública. É importante salientar que de nada serve uma boa política interna sem sua devida e continuada aplicação para se alcançar os resultados pretendidos.

Para que este trabalho alcance seus objetivos, é importante e também necessário identificar as principais características da incidência desse fenômeno, bem como sua compreensão quanto à dinâmica de suas oscilações.

\section{Discussão teórica}

Chiavenato (2004, p.577), diz que a Gestão de Pessoas é o "conjunto de políticas e práticas necessárias para conduzir os aspectos da posição gerencial relacionados com pessoas ou recursos humanos, incluindo recrutamento, seleção, treinamento, recompensas e avaliação do desempenho". Portanto na gestão de pessoas é refletida a cultura da organização, acompanhado de fatores relevantes como a estrutura organizacional, os processos internos, a tecnologia adotada pela organização e muitos outros fatores condicionantes. É notório que todas as atividades organizacionais estão interligadas entre si e relacionadas ao conhecimento, habilidade e ação das pessoas que sustentam o processo produtivo, e estas são responsáveis pelo desempenho da organização. 
Id on Line Revista Multidisciplinar e de Psicologia

Id on Line Revista Multidisciplinar e de Psicologia

Chiavenato (2004), também aponta como aspectos fundamentais para a Gestão de Pessoas, as seguintes proposições: As pessoas devem ser vistas como seres humanos e não como recursos da organização; as pessoas são ativadoras inteligentes de recursos organizacionais capazes de proporcionar uma constante renovação e de dinamizar a organização e as pessoas são vistas como parceiras da organização, comprometidas e vistas como parte integrante e importante nas tomadas de decisão.

Assim, é perceptível que os objetivos organizacionais são atingidos através das pessoas, mas essas mesmas pessoas possuem sonhos individuais e pessoais e para atingí-los se utilizam da organização. Portanto, é mais que evidente que haja uma verdadeira parceria entre empregador e empregado com objetivo de troca de incentivos e contribuições proporcionais, o que é salutar para ambas as partes, e dessa forma é possível conseguir um equilíbrio organizacional.

Segundo Lawler (1993), a motivação é considerada um fator crítico em qualquer planejamento organizacional e assim é importante verificar quais arranjos organizacionais e práticas gerenciais fazem sentido no intuito de não provocar um impacto que nos comportamentos individuais e organizacionais. Por isso é importante também compreender a teoria motivacional para se pensar analiticamente sobre todos os comportamentos nas organizações. Dessa forma compreende-se que o papel do gestor é criar um ambiente ou condições ambientais que provoquem e estimulem a motivação das pessoas para buscar satisfazer as suas próprias necessidades sem tampouco deixar suas obrigações organizacionais.

Dado a relevância e magnitude do trabalho policial, e o quanto sua atuação é tão perigosa quanto valorosa para a sociedade, é de fundamental importância que os profissionais da Polícia Militar estejam tão motivados a ponto de que sua atuação seja capaz de garantir eficiência na árdua tarefa de proteger o cidadão e qualidade de vida, segurança e saúde para si.

Os dados deste estudo podem subsidiar as instituições para uma capacitação continuada, com ênfase no comportamento organizacional e motivacional dos servidores, a fim de assegurar que estes profissionais possam trabalhar mais satisfeitos e reduzir o nível de periculosidade com o redobramento da atenção no trabalho e contenção da possibilidade de doenças causadas pelo estresse presente na atuação profissional.

Um questionamento poderá definir o nível de importância do estudo: a motivação do servidor público militar estadual pode ser provocada a partir da participação em eventos motivacionais melhorando sua produtividade e qualidade de vida no trabalho?

Assim, identificamos como objetivo geral: avaliar o nível motivacional dos servidores da Polícia Militar da Bahia, que atuam na Companhia Independente de Policiamento Tático sediada na cidade de Juazeiro, antes e após participarem de eventos motivacionais. E como objetivos específicos:

- Traçar o perfil sociodemográfico da população pesquisada;

- Avaliar o nível de satisfação do profissional para com seu trabalho e instituição; 
Id on Line Revista Multidisciplinar e de Psicoloqia

Id on Line Revista Multidisciplinar e de Psicologia

- Avaliar a percepção do profissional quanto ao reconhecimento recebido pela sua dedicação ao trabalho;

- Identificar se o profissional reconhece a importância da implementação de eventos motivacionais internos;

- Avaliar a percepção do servidor quanto ao seu comportamento após assistir palestras motivacionais e de qualidade de vida no trabalho;

\section{Método}

Trata-se de uma pesquisa descritiva, exploratória e de caráter qualitativo. A pesquisa descritiva descreve as características de determinada população ou fenômeno, ou o estabelecimento de relações entre variáveis, aplicando questionário e observação sistemática na coleta de dados. A pesquisa exploratória permite ao pesquisador maior familiaridade com o problema, tornando-o explicito, ou permitindo a construção de hipótese. Já a pesquisa quantitativa não requer o uso de técnicas estatísticas, os dados são avaliados indutivamente onde o pesquisador torna-se o elemento chave do processo. (MANHÂES, 2010).

A pesquisa foi realizada através de estudo de caso onde foi aplicado um questionário para avaliar o nível atual de satisfação e motivação e em seguida foram realizadas palestras motivacionais e sobre qualidade de vida no trabalho em reuniões programadas dentro da Companhia de Polícia Militar em Juazeiro, logo após, houve a aplicação de um outro questionário aos participantes para que os mesmos possam identificar se houve eficácia das palestras apresentadas no comportamento dos servidores. Os resultados da pesquisa foram integrados às informações teóricas aplicáveis por meio de análise indutiva para averiguar se houve positividade na aplicação dos eventos motivacionais. A população do estudo é composta por todos os participantes dos eventos que concordaram fazer parte da pesquisa.

O questionário, construído para o propósito da pesquisa, foi dividido em quatro seções, onde:

- A primeira seção buscou traçar o perfil sócio demográfico da população pesquisada;

- A segunda seção objetivou avaliar o nível de satisfação do profissional para com seu trabalho e instituição;

- A terceira seção procurou avaliar a percepção do profissional quanto à importância do seu trabalho e ao reconhecimento recebido pela sua dedicação ao trabalho;

- A quarta seção identificou se o profissional reconhece a importância da implementação de eventos motivacionais internos para melhorar seu nível de satisfação; 
Id on Line Revista Multidisciplinar e de Psicologia

Id on Line Revista Multidisciplinar e de Psicologia

Após a realização das palestras foi aplicado um novo questionário que objetivou avaliar a percepção do servidor quanto ao seu comportamento após assistir às palestras motivacionais e de qualidade de vida no trabalho.

\section{Análise de Dados}

Na primeira seção do questionário aplicado foram coletadas informações que expõem o perfil da população pesquisada com dados sobre sexo, grau de instrução, moradia, posses de bens e distância da residência para o trabalho.

A Companhia Independente de Policiamento Tático de Juazeiro, conhecida apenas como Rondesp Norte, é composta por 91 (noventa e um) policiais, incluindo o comandante e demais oficiais da unidade. O efetivo da Rondesp Norte é composto por $92 \%$ de profissionais do sexo masculino e $8 \%$ do sexo feminino.

Participaram da pesquisa a quantidade de 42 policiais, onde foi possível identificar que cerca de $71 \%$ destes possuem nível superior completo ou estão estudando faculdade, o que revela um alto nível de qualificação profissional.

Foi possível identificar também que $95 \%$ dos pesquisados residem na cidade onde trabalham ou em cidade vizinha e bem próxima do local de trabalho. Esse fator é importante para observar que estes profissionais não sofrem em viagens longas e estressantes para chegar no trabalho ou para retornar até suas residências. A pesquisa também revelou que $86 \%$ dos entrevistados moram em casa própria e apenas $14 \%$ em casa alugada e que $95 \%$ deles possuem algum tipo de transporte automotor (carro ou moto, ou carro e moto), o que sugere maior qualidade de vida destes profissionais. Os gráficos abaixo detalham esses dados:

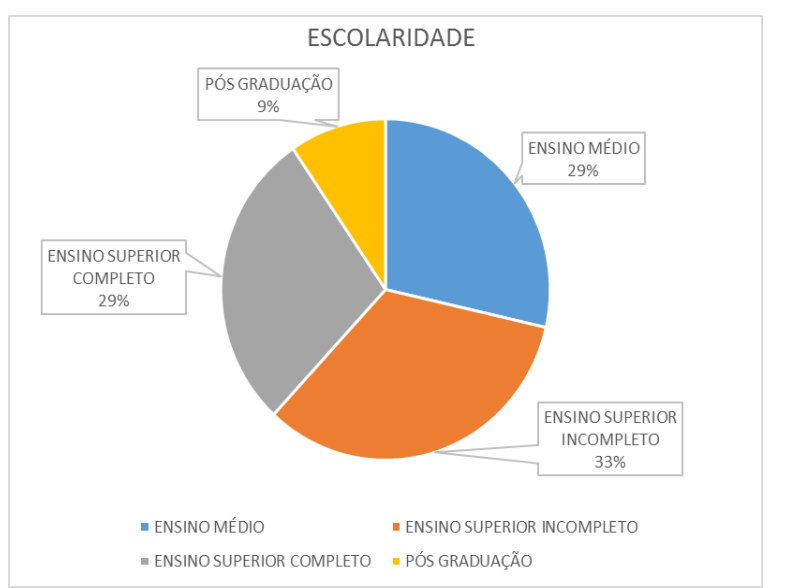

Fonte: elaborado pelo autor

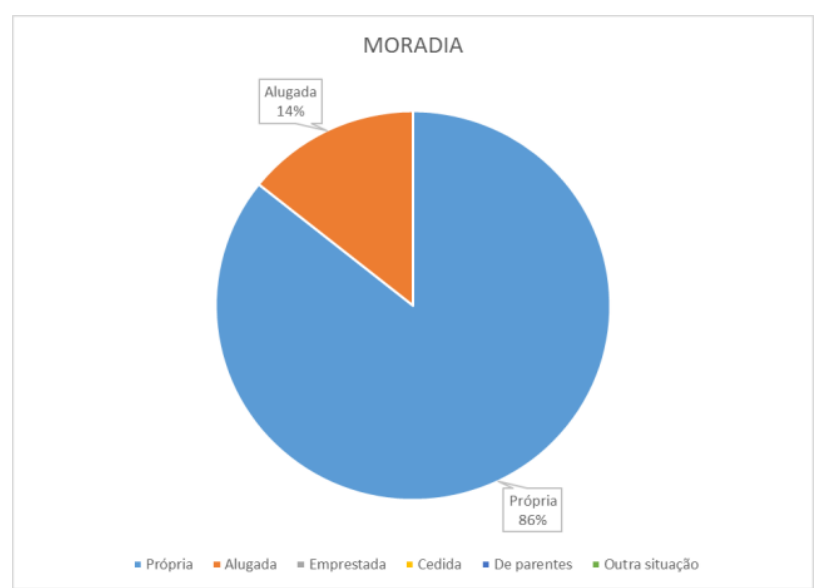

Fonte: elaborado pelo autor 
Id on Line Revista Multidisciplinar e de Psicologia

Id on Line Revista Multidisciplinar e de Psicologia

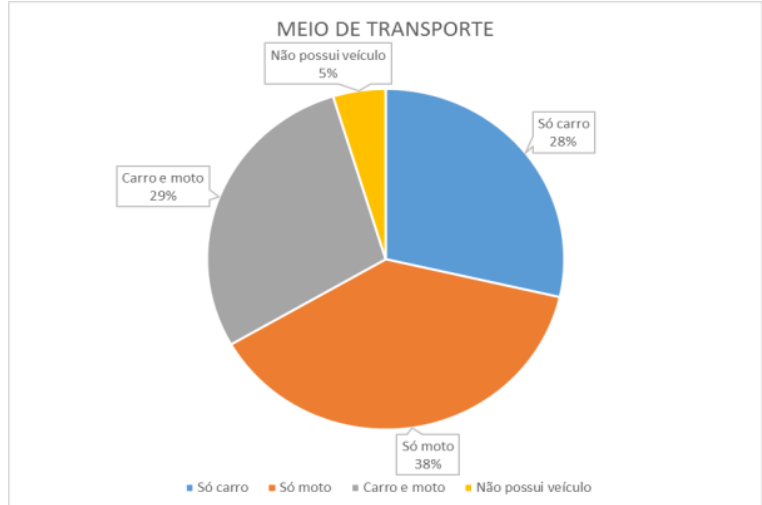

Fonte: elaborado pelo autor

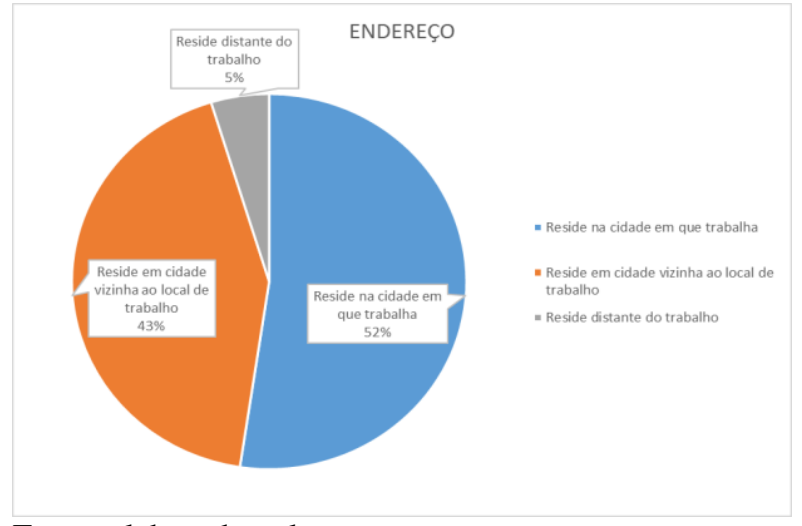

Fonte: elaborado pelo autor

Na segunda seção foi possível avaliar o nível de satisfação do profissional para com seu trabalho e instituição, onde foi possível perceber um nível moderado de satisfação salarial, um nível substancial de satisfação com o trabalho, a chefia e os colegas de profissão, mas por outro lado essa seção revelou um alto nível de insatisfação com a instituição. O bom nível de satisfação com o trabalho, a chefia e os colegas revela um ambiente salutar, mas a insatisfação com a instituição pode acarretar problemas para a gestão ao longo do tempo.

Os gráficos abaixo podem detalhar melhor os dados desta seção:

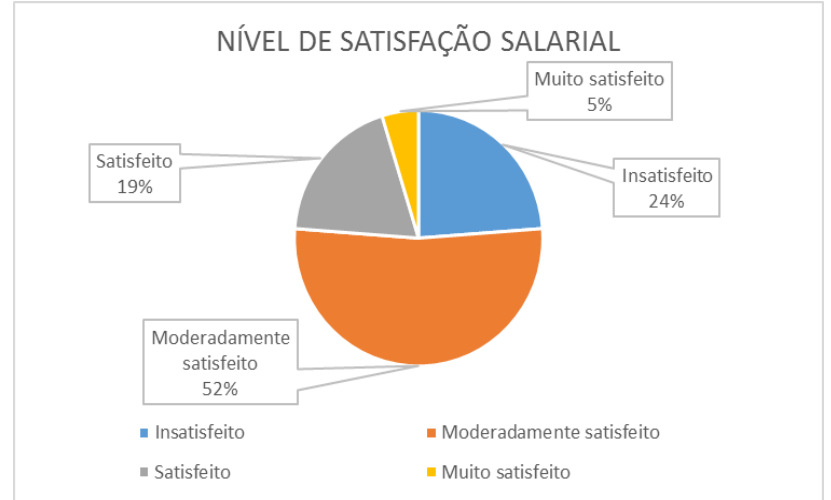

Fonte: elaborado pelo autor

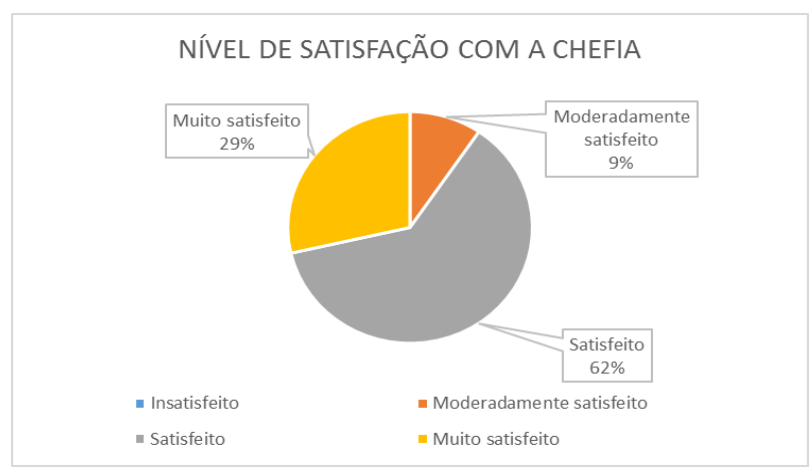

Fonte: elaborado pelo autor

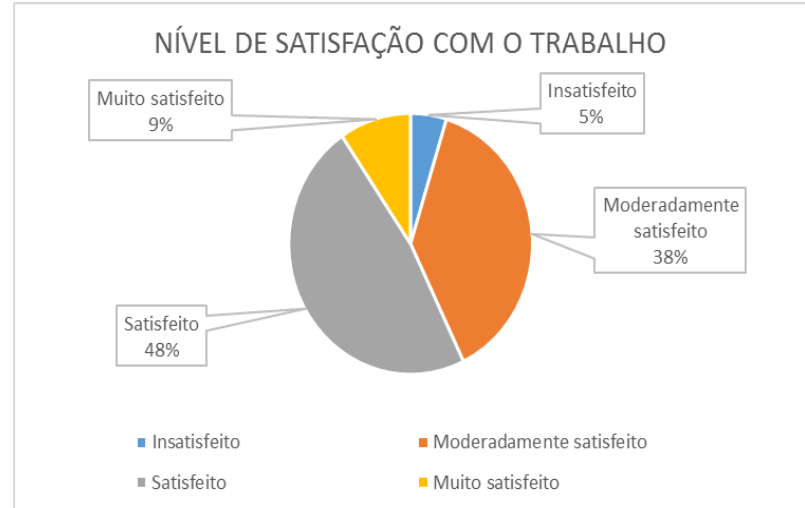

Fonte: elaborado pelo autor

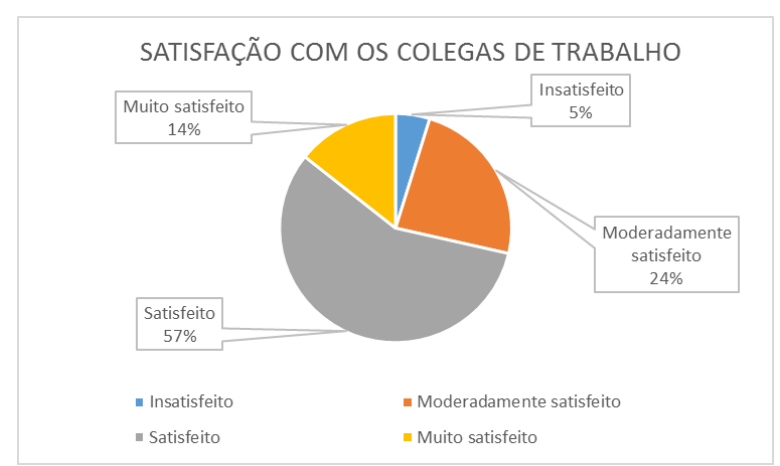

Fonte: elaborado pelo autor 
Id on Line Revista Multidisciplinar e de Psicologia

Id on Line Revista Multidisciplinar e de Psicologia

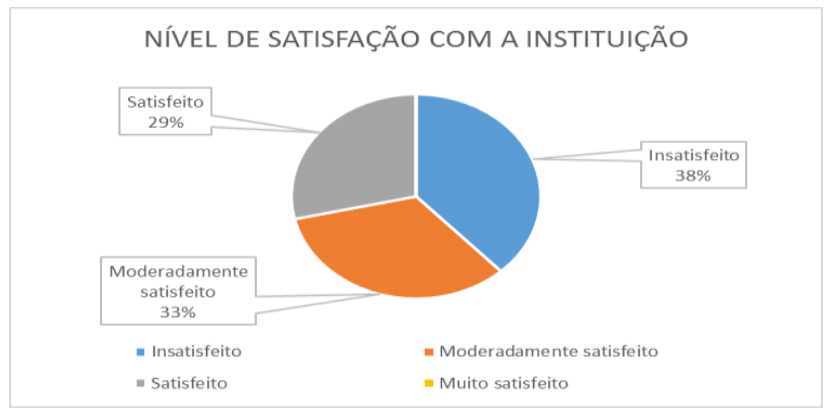

Fonte: elaborado pelo autor

A terceira seção procurou avaliar a percepção do profissional quanto à importância do seu trabalho e ao reconhecimento recebido pela sua dedicação ao trabalho. Nessa fase foi possível perceber que os profissionais compreendem que seu trabalho é de significativa importância tanto para a instituição quanto para a sociedade, mas estes não se sentem valorizados pela sua dedicação ao trabalho e isso aponta um fator de desmotivação no trabalho o que pode acarretar menor desempenho, déficit na qualidade de prestação dos serviços e perda de produtividade, e consequentemente maior índice de violência e riscos e perigos sociais.

Pode-se melhor visualizar os resultados desta fase nos gráficos a seguir:

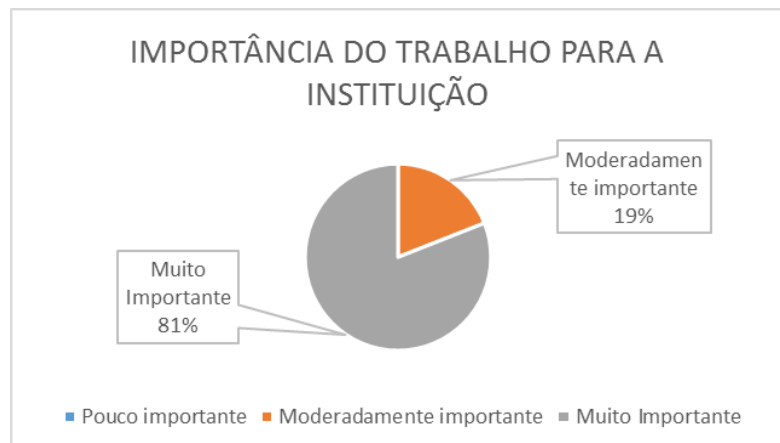

Fonte: elaborado pelo autor

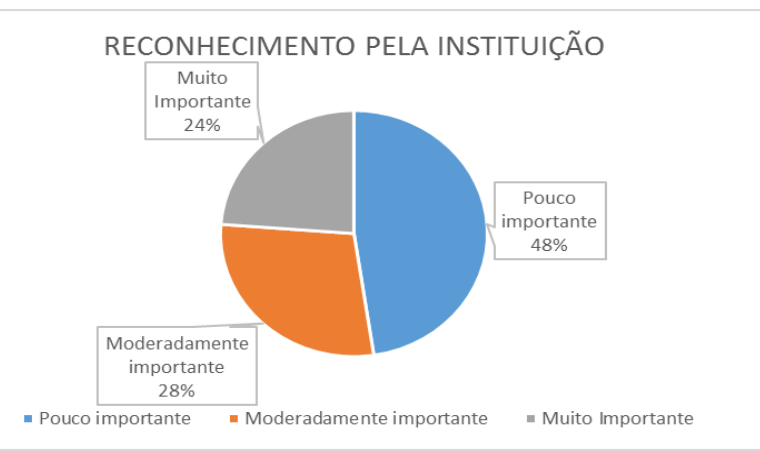

Fonte: elaborado pelo autor

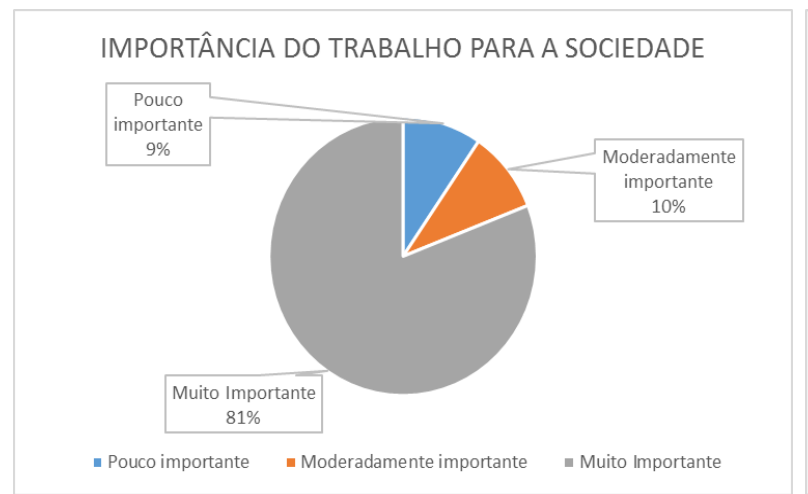

Fonte: elaborado pelo autor

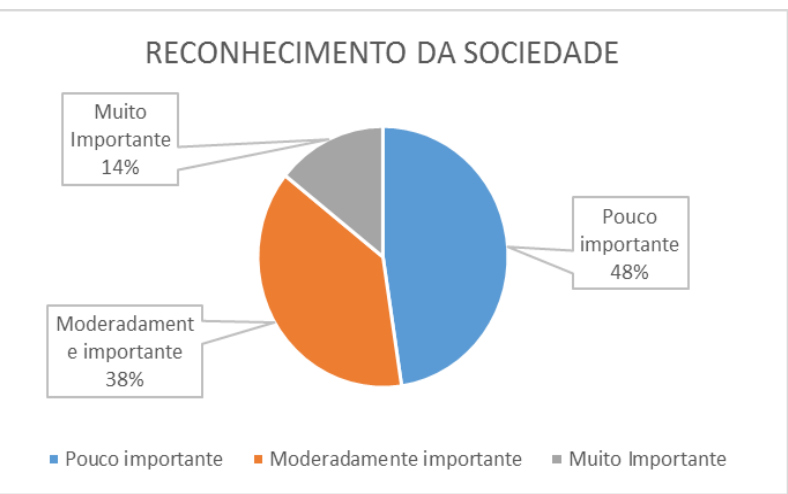

Fonte: elaborado pelo autor 
Id on Line Revista Multidisciplinar e de Psicologia

Id on Line Revista Multidisciplinar e de Psicologia

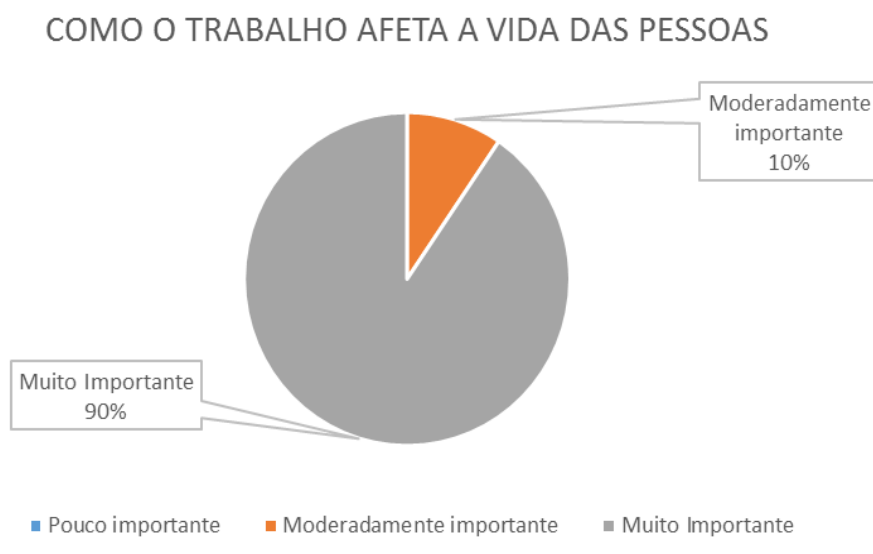

Fonte: elaborado pelo autor

A quarta seção identificou se o profissional reconhece a importância da implementação de eventos motivacionais internos para melhorar seu nível de satisfação. Aqui foi possível perceber que a instituição ou os seus gestores considera esporadicamente, ou desconsidera totalmente o estado psicoemocional dos servidores no dia a dia de trabalho, que a instituição não aplica ou aplica casualmente pesquisa de satisfação e que esta não costuma realizar eventos motivacionais e quando os realiza são insatisfatórios.

Esta situação pode ser avaliada como uma falha grave da gestão, visto que o trabalho policial é uma atividade de alto risco e os profissionais que a executam devem estar sendo avaliados constantemente para que suas ações sejam sempre embasadas na coerência, disciplina e racionalidade, pois uma simples falha pode colocar em risco a vida de muitas pessoas, inclusive dos atores da segurança pública. Como mostra os gráficos a seguir:

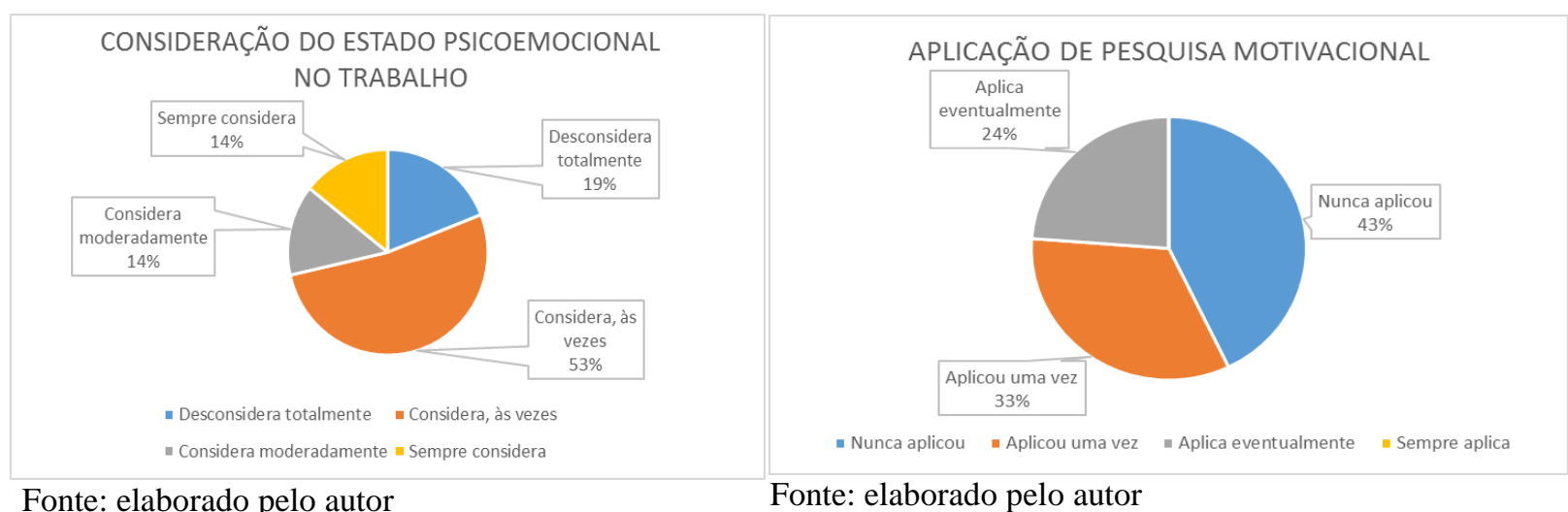


Id on Line Revista Multidisciplinar e de Psicoloqia

Id on Line Revista Multidisciplinar e de Psicologia

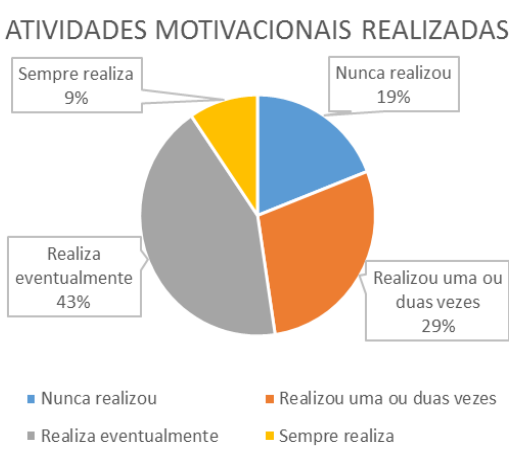

Fonte: elaborado pelo autor

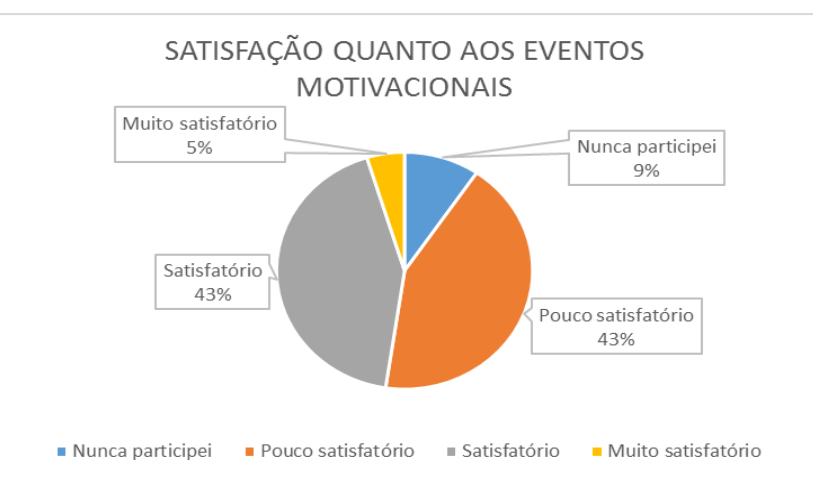

Fonte: elaborado pelo autor

Ainda nesta fase foi possível avaliar que os profissionais pesquisados acreditam na importância da promoção de eventos motivacionais como palestras, seminários, oficinas, workshops, shows, confraternizações, etc, e que estes têm potencial de melhorar o nível de satisfação da tropa e consequentemente o desempenho no trabalho. Como pode ser observado nos gráficos abaixo:

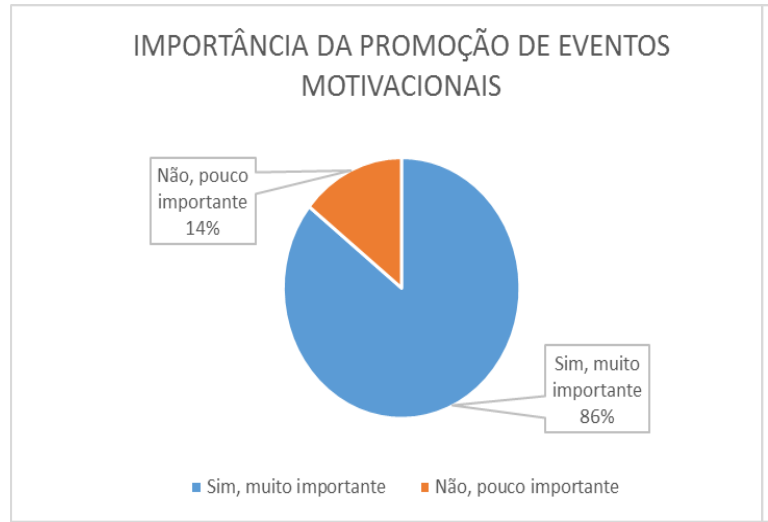

Fonte: elaborado pelo autor

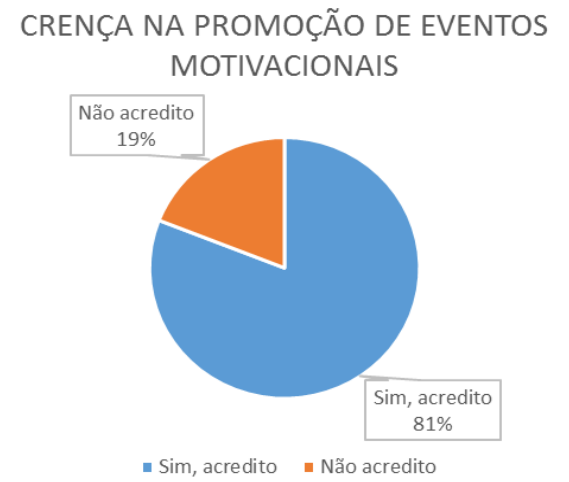

Fonte: elaborado pelo autor

Após esta pesquisa, o público alvo participou de uma palestra com o tema: Motivação e Qualidade de Vida no Trabalho, realizada no dia 26 de abril de 2016, às 09:00hs, no auditório do Grande Hotel de Juazeiro. Em seguida foi submetido a um novo questionário que buscou avaliar a perspectiva e qualidade do evento e assim percebeu-se que a palestra foi avaliada como muito relevante e que os temas abordados tiveram alto nível de importância para o crescimento profissional dos participantes e que teve excelente aceitação no que diz respeito ao nível de satisfação motivacional da tropa. Os policiais que participaram do evento responderam que se sentiam mais satisfeitos e que a realização periódica de eventos desta natureza era capaz de elevar a autoestima dos colaboradores e assim contribuir positivamente para a melhoria do seu trabalho.

Os gráficos a seguir podem demonstrar mais claramente os níveis que foram abordados: 
Id on Line Revista Multidisciplinar e de Psicologia

Id on Line Revista Multidisciplinar e de Psicologia
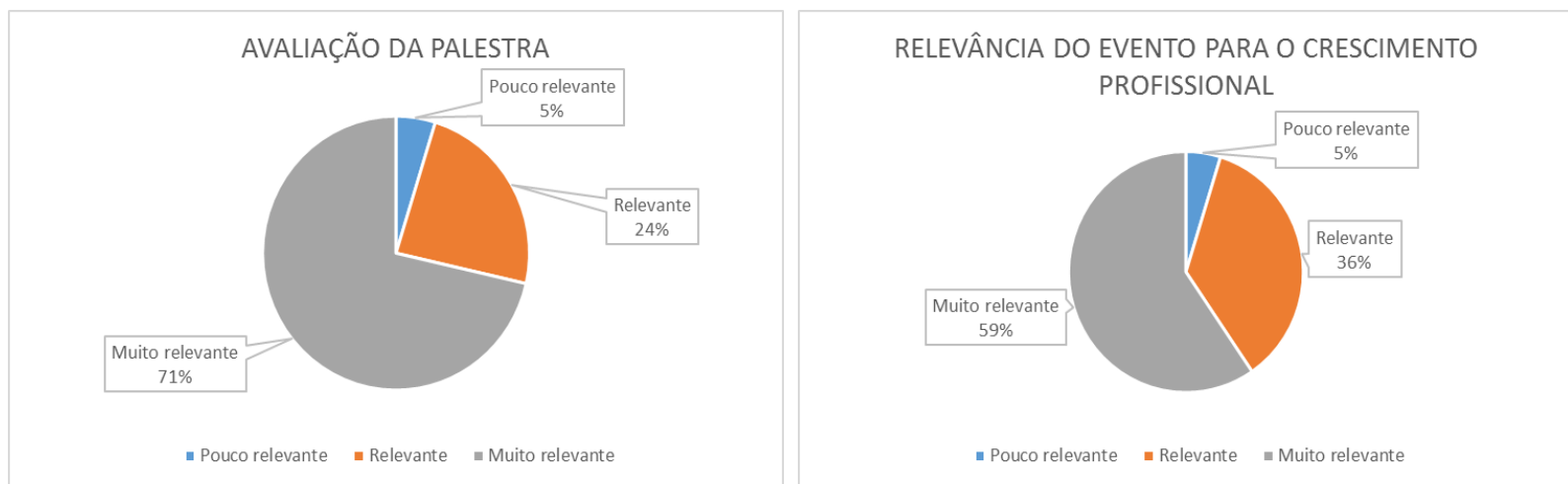

Fonte: elaborado pelo autor

Fonte: elaborado pelo autor

CONEXÃO DOS TEMAS COM COM A ATIVIDADE
PROFISSIONAL

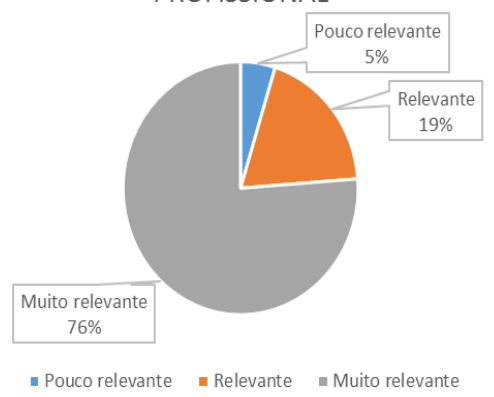

Fonte: elaborado pelo autor

ESTE TIPO DE EVENTO PODE MELHORAR SEU

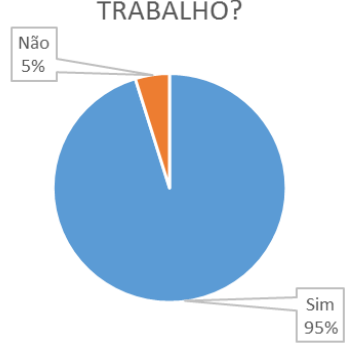

- Sim = Não

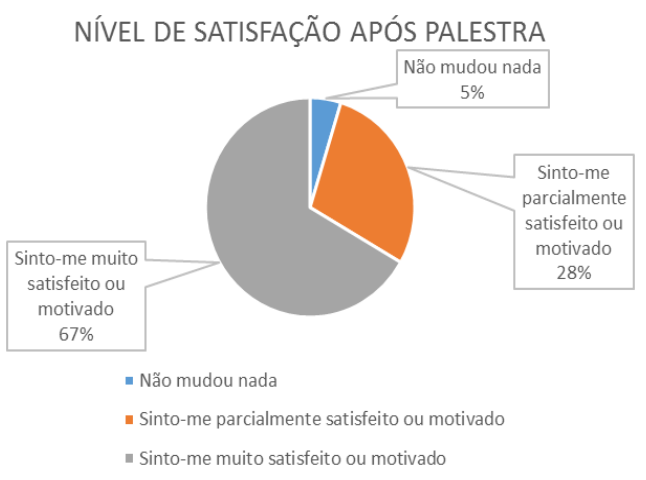

Fonte: elaborado pelo autor

Fonte: elaborado pelo autor

\section{Considerações finais}

Todo e qualquer gestor de uma organização, seja ela pública ou privada, sabe de perto os problemas que tem enfrentado para manter seus servidores ou colaboradores empenhados a cumprir as metas e objetivos da instituição. A exigência por uma determinada produtividade pode acarretar diversos problemas no ânimo dos profissionais que executam alguma atividade, especialmente o trabalho de polícia que é uma atividade diferenciada. E esses problemas podem se agravar quando a meta não é alcançada e as cobranças aumentam. 
Id on Line Revista Multidisciplinar e de Psicoloqia

Id on Line Revista Multidisciplinar e de Psicologia

É justamente nesse cenário que surge a necessidade de reestabelecer a motivação dos colaboradores, e nesse contexto a realização de eventos motivacionais podem fazer a diferença em um ambiente tão complexo. A realização de palestras, oficinas, seminários, workshops, confraternizações é capaz de impulsionar a reflexão dos participantes e fazer com que os mesmos sintam-se capazes de realizar mais que do imagina e de uma forma mais prazerosa.

A palestra realizada com o público alvo deste trabalho favoreceu uma autorreflexão sobre atitudes pessoais e profissionais; sobre possíveis aflições e/ou insatisfações, bem como um repensar de aspectos mais saudáveis do comportamento, capazes de dotar o indivíduo de recursos emocionais promotores de uma maior resiliência.

Desta forma foi possível perceber que a realização deste tipo de evento parece capaz de melhorar a qualidade de vida dos profissionais de polícia que dia após dia deixam suas casas e saem sem saber se voltam devido ao alto grau de risco da atividade.

É então que entra a pessoa do gestor público que agora tem ciência da atual situação e tem um grande desafio que é de dar diligência à aplicação de políticas que venham garantir a integridade física, psicológica, emocional e social dos servidores sob seu comando.

Portanto, entende-se que o objetivo deste trabalho foi alcançado e que, é possível melhorar a gestão da qualidade de vida dos integrantes da segurança pública para que assim estes possam prestar um melhor serviço à sociedade. Como dito anteriormente, é importante salientar que de nada serve uma boa política interna sem sua devida e continuada aplicação para se alcançar os resultados pretendidos.

\section{Referências}

CHIAVENATO, Idalberto. Gestão de Pessoas: o novo papel dos recursos humanos nas organizações. Rio de Janeiro: Elsevier, 2004.

LAWLER, Edward E. Motivação nas organizações de trabalho. In BERGAMINI, Cecília W. e CODA, Roberto. Psicodinâmica da vida organizacional: Motivação e Liderança. $2^{a}$ ed. São Paulo: Atlas, 1997.

MANHÃES, Fernanda Castro. Metodologia da pesquisa: guia prático - Itabuna: Via Litterarum, 2010.

GIDDENS, A. Para além da esquerda e da direita. São Paulo: Ed. da Unesp, 1966. 
Id on Line Revista Multidisciplinar e de Psicologia

Id on Line Revista Multidisciplinar e de Psicologia

\section{Como citar este artigo (Formato ABNT):}

FRANÇA, M.E.; CAFFÉ FILHO, H.P. Motivação no Trabalho: uma avaliação do Nível de Satisfação de Policiais Militares. Id on Line Revista Multidisciplinar e de Psicologia, Julho de 2016, vol.10, n.30, Supl. 2, . p. 40-52. ISSN 1981-1179.

Recebido: 02/05/2016.

Aceito: 06/05/2016 